\title{
Surgical management of avascular necrosis of femoral head in young adults treated with uncemented total hip replacement
}

\author{
Vijay Bhaskar Reddy, N. Brahma Chary, Kacham Nikitha
}

Department of Orthopaedics, MNR Medical College and Hospital, Sangareddy, Telangana, India

Received: 18 September 2021

Accepted: 19 October 2021

\section{*Correspondence:}

Dr. N. Brahma Chary,

E-mail: drnbrahmachary22@gmail.com

Copyright: (C) the author(s), publisher and licensee Medip Academy. This is an open-access article distributed under the terms of the Creative Commons Attribution Non-Commercial License, which permits unrestricted non-commercial use, distribution, and reproduction in any medium, provided the original work is properly cited.

\begin{abstract}
Background: Normal hip joint is subjected to many stresses during daily activities performed by an individual. Since it is one of the major weight bearing joints of the body, its normal function is necessary for daily activities. Avascular necrosis $(\mathrm{AVN})$ of the femoral head is one of the common causes of painful hip in a young adult. Core decompression, fibular sturt graft can be considered in early stages, total hip arthroplasty in later stages of AVN of femoral head.

Methods: This is a retrospective study of 30 patients following uncemented total hip replacement, who were operated between August 2017 and March 2020 at MNR medical college and hospital, Sangareddy. They were followed up for a minimum period of 1 year and evaluated using Harris hip scoring system. Harris hip score is designed specifically for measuring functional outcomes in hip arthroplasty.

Results: There was a significant improvement in function as measured with the Harris hip score. The overall preoperative Harris hip score was 43, which remarkably improved to 89 postoperatively. The results observed, showed that all patients had good to excellent results, (Harris hip score $\geq 0$ ) thus showing a good degree of pain relief, improvement in function and range of motion.

Conclusions: Although the use of total hip arthroplasty in young patients will more likely necessitate future revision surgery, the consistent relief of pain and good functional results have made this procedure an attractive treatment choice for the debilitating arthritis resulting from osteonecrosis of the femoral head.
\end{abstract}

Keywords: Harris hip score, Avascular necrosis, Uncemented total hip replacement

\section{INTRODUCTION}

Inadequate blood flow leads osteocyte death, which results in osteonecrosis of the femoral head (ONFH). Following that, the femoral head collapses and the advanced joint degradation sets in. ONFH is one of the most common causes of hip arthroplasty in young people, resulting in considerable handicap during the most productive years of life. ONFH has etiologies that include both traumatic and nontraumatic causes. Corticosteroid drugs, hip fractures and dislocations, and prolonged alcohol consumption are some of the most common causes. It's idiopathic in about $30 \%$ of individuals. Males are more likely to be affected by bilateral presentation. Males are more usually affected than females, and bilateral presentation is common. In roughly 55 percent of patients, the contralateral hip may be damaged within two years. Around $75 \%$ of patients with other sites of disease will develop ONFH at the same time. ${ }^{1}$

The hip joint is painless in the early stages of ONFH. However, as the condition progresses, it becomes uncomfortable and hip range of motion is limited. ONFH has a variety of diagnostic and therapeutic options, however none of them are totally accurate or successful. Earliest X-ray findings of ONFH take at least 2 months to develop but may take as long as 6 months. Sclerosis and cystic changes are early radiographical changes. With progression of disease, there is asphericity of femoral head 
(femoral head collapse) and joint space reduction (secondary arthritis). ${ }^{2,3}$ Surgical treatment of avascular necrosis (AVN) of head of femur include core decompression, osteotomies, non-vascularized bone grafting, free vascularized fibular grafts, hip resurfacing, bipolar hip arthroplasty (BHA) and total hip arthroplasty. Normal hip joint is subjected to many stresses during daily activities performed by an individual. Since it is one of the major weight bearing joints of the body, its normal function is necessary for daily activities. Avascular necrosis (AVN) of the femoral head is one of the common causes of painful hip in a young adult. Core decompression, fibular sturt graft can be considered in early stages, total hip arthroplasty in later stages of AVN of femoral head. To study surgical and functional outcome following uncemented total hip arthroplasty in young adults.

\section{METHODS}

Study was carried out at MNR Medical college and hospital, Sangareddy, where 30 patients were operated, 36 Total hip replacements done on 30 patients, between August 2017 to March 2020. They were followed up for a minimum period of 1 year and evaluated for surgical and functional outcome using X-rays and Harris hip score. Patients were followed at 1month, 3 months, 6 months and 1 -year, post-surgery. The pre and post-operative pain, deformity and functional outcomes were compared.

\section{Inclusion criteria}

Age 20 - 35years. Both male and female. Ficat-Arlet type III -IV. Idiopathic. Both bilateral and unilateral avascular necrosis of femoral head patients.

\section{Exclusion criteria}

Age $<20$ years and $>35$ years. Infective conditions. Previous history of surgery to hip including arthroscopy. Progressive neuromuscular disorders. Revision THR. Dermatological conditions around hip.

\section{Pre-operative evaluation}

Detailed history of all patients was taken. All patients were assessed clinically and functionally using the Harris hip score. The preoperative medical evaluations of all patients were done to evaluate any potential complications that can be life-threatening or limb-threatening.

\section{Radiographic assessment}

Standard guidelines were utilized to obtain hip radiographs - standing anteroposterior view.

\section{Operative technique}

All the patients after thorough pre operative evaluation, they were taken up for surgery under combined epidural and spinal anesthesia. All patients received $1 \mathrm{gm}$ of Ceftriaxone 15mins prior to surgery. Using Southern Moore approach, incision was taken with patient in lateral decubitus position. The Fascia lata incision is taken. Gluteus maximus muscle is split. Short external rotators piriformis and Obturator internus are dissected and retracted. Longitudinal or $\mathrm{T}$ - shaped capsular incision is taken. Hip dislocation is done with Internal rotation. Arthritic femoral head is cut upto the femoral neck leaving the calcar intact. Acetabular reaming is done. Appropriate acetabular cup size trial is done. Finally, Hydroxyapatite coated acetabular cup implant is fixed with 2 screws. Femoral canal broaching is done. Trial femoral stem is placed. Hydroxyapatite coated femoral stem of appropriate size is fixed. Femoral head of different sizes trial is done. Appropriate size of femoral head is placed. Range of movements of the hip is checked and evaluated for stability. The hip is reduced. The capsule is closed. Short external rotators suturing is done. Wound closed in layers with drain in place. Bilateral AVN patients are operated in staged manner with 1 week apart.

\section{Statistical analysis}

The graph pad prism software version 6.01 will be used to analyze the data. For continuous data, mean SD was used, median IQR (Inter Quartile Range) was used for score data, and percentages were used for categorical data. For categorical data, a fischers exact test / chi square test was used to determine the relationship between variables. We regarded all $\mathrm{p}$ values less than 0.05 to be statistically significant.

\section{RESULTS}

This is a retrospective study of 30 patients who underwent uncemented total hip replacement. All patients are mobilized from post-op day 6. Unilateral operated patients are discharged after 1-week, bilateral patients are discharged after 2 weeks. Patients were evaluated clinically and radiologically at an interval of 1 month, 3 months, 6 months and 1 year in Orthopaedic OPD.

The majority of the patients were from age group of 20-35 years. This age group has the causes as idiopathic or related to alcohol or steroid intake. AVN of the femoral head is common in young individuals. Out of 30 patients, 24 were males and 6 were females. The overall male to female ratio was $4: 1$.

Table 1: Outcome categories for Harris hip score, reported based on following cut points.

\begin{tabular}{|ll|}
\hline Outcome & Score \\
\hline Excellent & $90-100$ \\
\hline Good & $80-89$ \\
\hline Fair & $70-79$ \\
\hline Poor & $<70$ \\
\hline
\end{tabular}


Out of 30 patients, $8(27 \%)$ had bilateral involvement of hip joint. The remaining 13 patients $(65 \%)$ had unilateral hip involvement.

Of the 30 cases of AVN of head of the femur, there were 9 cases where there was history of chronic alcohol intake and among them 2 patient was on steroids for a long time for the treatment of bronchial asthma.

Table 2: Demographic details of study.

\begin{tabular}{|lll|}
\hline Patient details & $\begin{array}{l}\text { Number of } \\
\text { subjects }\end{array}$ & Percentages \\
\hline Age in years & & \\
\hline $20-25$ & 7 & 23.3 \\
\hline $26-30$ & 6 & 20 \\
\hline $31-35$ & 17 & 56.7 \\
\hline Gender & & \\
\hline Males & 24 & 80 \\
\hline Females & 6 & 20 \\
\hline Involvement & & \\
\hline Bilateral & 8 & 27 \\
\hline Unilateral & 22 & 72 \\
\hline
\end{tabular}

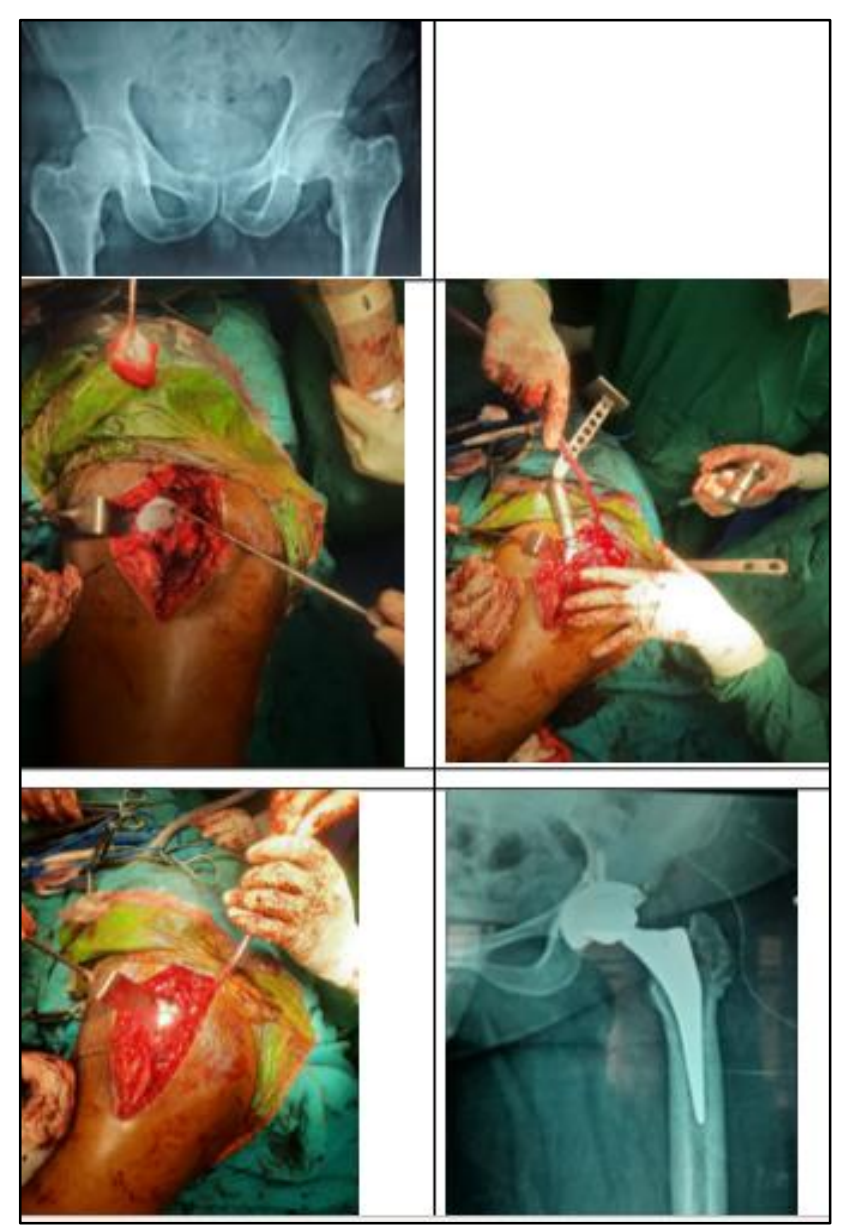

Figure 1:

There was a significant improvement in function as measured with the Harris hip score. The overall preoperative Harris hip score was 43, which remarkably improved to 89 postoperatively. The results observed, showed that all patients had good to excellent results, (Harris hip score $\geq 80$ ) thus showing a good degree of pain relief, improvement in function and range of motion. The most important improvement was seen with regard to pain, with all the 30 patients attaining a pain score of 44 (complete relief of pain) after 12 months of surgery. The outcome categories based on harris hip scoring system: excellent (90-100), good (80-89), fair (70-79) and poor $(<70)$.

\section{DISCUSSION}

In this study, 30 cases of advanced AVN of the femoral head (Ficat and Arlet stage III and IV) were treated by primary total hip arthroplasty. The study was undertaken to know the vital role of total hip replacement in AVN of head of the femur. AVN of head of femur forms one of the major indications for total hip replacement. Between 5$12 \%$ of the total hip replacements are performed in patients who have AVN of femoral head. Total hip arthroplasty is the only predictable effective treatment of AVN of the femoral head when the disease process has reached Ficat and Arlet stages III and IV.

According to J. P. Garino and M. E. Steinberg, using modern cement techniques and components, total hip arthroplasty can give excellent results in young patients with AVN and may be the treatment of choice when reconstructive surgery is required. Although wear of the bearing surface continues to limit the long term success rate, cementless total hip arthroplasty remains a reasonable treatment option for advanced osteonecrosis of the femoral head. ${ }^{4}$

Patients with osteonecrosis of the femoral head tend to be very young, which means that the outcome of a cemented or hybrid total hip arthroplasty can he expected to be suboptimal. The inferior results for patients with osteonecrosis of the femoral head compared with patients with osteoarthritis may in some instances relate to the younger age of the patients affected by osteonecrosis of the femoral head. 5

The results of the present study, although at short term are encouraging. We have demonstrated that the results of total hip arthroplasty with a hydroxyapatite-coated prosthesis in young patients with osteonecrosis of the femoral head were similar to the results seen in a matched group of patients with osteoarthritis. Long-term results are needed to assess the longevity of total hip arthroplasty. It is important to point out, however, that the survivorship of $96 \%$ for the hips in our extremely young patients is better than has been reported previously. ${ }^{6}$

Cornell and coworkers" found similar poor results in a study of twenty-four patients (twenty-eight hips) at a mean duration of follow-up of ninety-one months (range, sixty to120 months). At the time of final follow-up, eleven hips 
required revision total hip arthroplasty, indicating a $39 \%$ failure rate. ${ }^{7}$

Total hip replacement, since its advent, has immensely decreased the sufferings, who was rendered unhappy and crippled due to variety of hip diseases. Previously it was thought that only older people should be considered for total hip replacement, but current trends and studies show that younger age groups are equally benefited though there are some problems. 8 .9 Although the use of total hip arthroplasty in young patients will more likely necessitate future reconstruction, the consistent relief of pain and good functional results have made this procedure an attractive treatment choice for the debilitating arthritis resulting from osteonecrosis of the femoral head. After total hip replacement, patients have shown significant improvement in the range of motion of joint and relief from pain and deformities. Most of the patients have resumed their jobs and are satisfied. Our study stresses the fact that total hip arthroplasty is a boon for patients of advanced AVN of femoral head, as life is movement and movement is life. ${ }^{10}$

\section{CONCLUSION}

Although the use of total hip arthroplasty in young patients will more likely necessitate future revision surgery, the consistent relief of pain and good functional results have made this procedure an attractive treatment choice for the debilitating arthritis resulting from osteonecrosis of the femoral head. The present study included 30 cases of advanced AVN of femoral head. The patients were crippled due to pain, inability to carry out day-to-day activities, loss of movements and deformities of the hip joints. After total hip replacement, patients have shown significant improvement in the range of motion of joint and relief from pain and deformities.

Funding: No funding sources Conflict of interest: None declared

Ethical approval: The study was approved by the institutional ethics committee

\section{REFERENCES}

1. Babhulkar S, Kulkarni SS. Avascular necrosis of the femoral head. In: Recent advances in Orthopaedics. 1985;359-81.

2. Kakaria HL, Sharma AK, Sebastian B. Total Hip Replacement in Avascular Necrosis of Femoral Head. Med J Armed Forces India. 2005;61(1):33-5.

3. Fairbank C, Bhatia D, Jinnah RH, Hungerford DS. Long term results of core decompression of ischaemic necrosis of the femoral head. J Bone Joint Surg. 1995;77:42-9.

4. Garino JP, Steinberg ME. Total hip arthroplasty inpatients with avascular necrosis of the femoral head. 2 to 10 years follow-up. Clin Ortho. 1997;334:10815.

5. Callaghan JJ, Forest EE, Olejniczak JP, Goetz DD, Johnston RC. Charnley total hip arthroplasty in patients less than fifty years old. A twenty to twentyfive-year follow-up note. J Bone Joint Surg Am. 1998;80(5):704-14.

6. Lewthwaite SC, Squires B, Gie GA, Timperley AJ, Ling RS. The Exeter Universal hip in patients 50 years or younger at 10-17 years' followup. Clin Orthop Relat Res. 2008;466(2):324-31.

7. Cornell CN, Ranawat CS. Survivorship analysis of total hip replacements. Results in a series of active patients who were less than fifty-five years old. J Bone Joint Surg Am. 1986;68(9):1430-4.

8. Chan YS, Shih $\mathrm{CH}$. Bipolar versus total hip arthroplasty for hip osteonecrosis in the same patient. Clin Orho. 2000;379:169-77.

9. Kim YH, Oh SH, Kim JS, Koo KH. Contemporary total hip arthroplasty with and without cement inpatients with osteonecrosis of the femoral head. J Bone Joint Surg Am. 2003;85-A(4):675-81.

10. Nagi ON, Dhillon MS, Sharma S. Total hip arthroplasty for avascular necrosis of the femoral head. Indian Journal of Orthopaedics. 1992;26:1747.

Cite this article as: Reddy VB, Chary NB, Nikitha K. Surgical management of avascular necrosis of femoral head in young adults treated with uncemented total hip replacement. Int J Res Orthop 2021;7:1166-9. 